\title{
KNOWLEDGE, ATTITUDE, PRACTICE, AND PERCEPTION TOWARDS COVID-19 IN NORTH EASTERN STATES OF INDIA: AN ONLINE CROSS SECTIONAL STUDY
}

\author{
AMIT SRIVASTAVA ${ }^{1}$, RENU BALA ${ }^{1 *}$, RATAN CHANDRA SHIL ${ }^{2}$, PRABIN KUMAR SHAW ${ }^{3}$, LIYI KARSO ${ }^{4}$, \\ HIMADRI BHAUMIK ${ }^{5}$, SANTOSH KUMAR TAMANG ${ }^{6}$, BAIDURJYA BHATTACHARJEE ${ }^{7}$, TAPAN NATH ${ }^{8}$, \\ ABHIJIT CHAKMA ${ }^{2}$, PRASENJIT SINHA ${ }^{9}$
}

\begin{abstract}
${ }^{1}$ Regional Research Institute for Homoeopathy, Imphal, Manipur, India. ${ }^{2}$ Regional Research Institute for Homoeopathy, Agartala, Tripura, India. ${ }^{3}$ Department of Materia Medica, The Calcutta Homoeopathic Medical College and Hospital, Kolkata, West Bengal, India. ${ }^{4}$ Regional Research Institute for Homoeopathy, Guwahati, Assam, India. ${ }^{5}$ Department of Materia Medica, North Eastern Institute of Ayurveda and Homoeopathy, Shillong, Meghalaya, India. ${ }^{6}$ Clinical Research Unit, Gangtok, Sikkim, India. ${ }^{7}$ Clinical Research Unit for Homoeopathy, Aizawl, Mizoram, India. ${ }^{8}$ Department of Case Taking and Repertory, North Eastern Institute of Ayurveda and Homoeopathy, Shillong, Meghalaya, India. ${ }^{9}$ Department of Biostatistics, Tripura University, Agartala, Tripura, India. Email: drrenu3011@gmail.com
\end{abstract}

Received: 08 September 2020, Revised and Accepted: 15 October 2020

ABSTRACT

Objective: The study aimed to assess knowledge, attitude, practices, and perception (KAP) toward COVID-19 among the population of eight North Eastern (NE) states of India.

Methods: A cross-sectional study from June 30 to July 13, 2020 was carried out through a self-reported, structured questionnaire that was circulated online to participants of age group of 18 years or above. Convenient sampling was used to recruit respondents for the study.

Results: The study received responses from 8309 participants. Key findings revealed that most respondents had good knowledge of preventive measures and common symptoms of COVID-19. The majority of the respondents showed a good attitude and adopted preventive practices. The mean score of knowledge was 7.137, attitude was 16.132 , practice was 9.379 , and perception was 13.583 . The scores of four KAP categories significantly differed across most of the demographic variables $(\mathrm{p}<0.001)$. The majority of people took homoeopathic medicine as prophylaxis for immune booster.

Conclusion: The study highlights that the focus on behavioral change communication in all the NE states could be strengthened, especially in rural areas. Advocacy based on the comprehensive list of symptoms for COVID-19 may also be bolstered. There is scope for strategically promoting knowledge, immunity boosting, and self-care practices suggested in the AYUSH systems of medicine.

Keywords: Attitude, COVID-19, Knowledge, North East India, Perception, Practices

(C) 2020 The Authors. Published by Innovare Academic Sciences Pvt Ltd. This is an open access article under the CC BY license (http://creativecommons. org/licenses/by/4. 0/) DOI: http://dx.doi.org/10.22159/ajpcr.2020.v13i12.39677

\section{INTRODUCTION}

The coronavirus disease 2019 (COVID-19) emerged in Wuhan, China at the end of 2019 [1]. On January 30, 2020, the World Health Organization (WHO) declared the outbreak of novel coronavirus (2019$\mathrm{nCoV}$ ) a Public Health Emergency of International Concern [2]. On March 11, 2020, the Government of India (GOI) invoked powers under the Epidemic Diseases Act, 1897 and declared COVID-19 a "notified disaster" under the Disaster Management Act 2005.

North East (NE) India comprises eight states namely Arunachal Pradesh (AP), Assam, Manipur, Meghalaya, Mizoram, Nagaland, Sikkim, and Tripura. The first case of COVID-19 in the NE Region (NER) was reported from Manipur followed by Mizoram with Meghalaya being the last [3]. As on June 30, 2020 (when this study was undertaken), globally 10 million positive cases of COVID-19 and 503,862 deaths were recorded while India witnessed 5,82,774 cases among which NE states tally was 11,391 with 14 deceased [4,5].

Many of the facts on pandemic keep on changing and many myths are prevalent causing confusion and panic in the public. The knowledge, attitudes, and practices (KAP) toward COVID-19 play an integral role in determining a society's readiness to accept behavioral change measures. Many KAP studies have been conducted in different parts of the world with similar objective [6-9]. To the best of our knowledge, so far, no prior study has assessed the KAP related to COVID-19 among the NE India population. It is imperative to assess KAP among people of NER that will aid the authorities in addressing future health interventions involving COVID-19.

\section{METHODS}

Study setting

An online cross-sectional study was conducted from June 30, 2020 to July 13, 2020 among the general population in eight (NE) states of India. Participants aged 18 years or above and who agree to participate in the survey were included in the study.

\section{Study procedure}

Complying with the guidelines on maintaining physical distancing, a web-based collection of data using Google form was adopted. A convenient sampling method was chosen and Google form was circulated widely through text message and social media platforms such as Facebook and WhatsApp. The Non-Government Organizations (NGOs) and local clubs were approached to circulate the Google forms widely through their network. The people in villages were approached during the awareness drive for COVID-19 by paying home-to-home visits and also the patients registered at research institutes were informed about the study on the telephone. If agreed, a link of Google form was sent on their mobile number as a text message with a request to get it filled by the other family members also. The data from Google form were automatically stored in a spreadsheet on Google drive. No incentive was offered to any participant in the survey.

The study was approved by the Institutional Ethical Committee of Regional Research Institute for Homoeopathy, Imphal. The development and reporting of the survey followed the Checklist for Reporting Results of Internet E-survey (CHERRIES) guidelines [10]. 
Study instruments

The self-reported questionnaire was developed as per the information available on websites of the Ministry of Health and Family Welfare (MoHFW), GOI [11], Ministry of AYUSH, GOI [12], WHO [1], and Centers for Disease Control and Prevention (CDC), United States of America [13]. KAP study conducted previously was also referred to while developing the questionnaire in the English language only [9]. The draft questionnaire was sent to ten experts in the eight NE states and the final version was prepared after the consensus of the experts.

In total, there were three sections in the study. The first section informed the participants about the background, objectives of the study, and confidentiality of identity. Respondents who consented to willingly participate in the study would click the "Continue" button and would then be directed to questions on socio-demographic characteristics. The second section assessed participants' knowledge of COVID-19 consisting of ten items with three options "Yes," "No," and "I don't know." A correct response was assigned 1 point while a wrong/don't know response was assigned zero point. The first question on symptomatology has 14 subquestions whose average was calculated and added to the remaining nine questions to get total knowledge score, which ranged from 0 to 10 , with higher scores indicating better knowledge of COVID-19.

The third section assessed participants' attitudes (four items), practices (six items), and perception (four items) toward COVID-19. For attitude and perception respondents were asked to state their level of agreement on a 5 -points Likert scale ("strongly disagree=1," "disagree=2," "neutral=3," "agree=4," or "strongly agree=5"). For practices, responses were collected following three-point Likert scale ("always=2," "sometimes=1," or "never=0"). The response to first question under the perception category was reversed. The total score was calculated by adding the respondent's answer to each question. The attitude and perception score ranged from 4 to 20 while practices score ranged from 0 to 12 with higher scores indicating better attitude, practices, and perception.

\section{Statistical analysis}

Fully completed questionnaires were extracted from Google Forms and exported to Microsoft Excel 2016 for cleaning and coding which was analyzed using SYSTAT 13 software. The score for knowledge, attitude, practices, and perception was divided into quartiles with $>75 \%$ indicating good, $50-75 \%$ average, $25-50 \%$ poor, and $<25 \%$ very poor response under each section.

Frequency and percentage of correct knowledge response and different attitude, practices, and perception were described. The independent sample t-test, analysis of variance (ANOVA), and Chi-square test were used as appropriate for finding a significant difference in KAP categories scores based on demographic variables. The statistical significance level was set at $\mathrm{p}<0.05$.

\section{RESULTS}

\section{Socio-demographic characteristics}

Responses from 8324 participants were received in the study and after removing incomplete entries the final dataset consisted of 8309 responses. The demographic characteristics of the study participants are given in Table 1 . The study generated response from all the eight states of NE India with maximum from Manipur $(n=3081 ; 37.08 \%)$ and Tripura (2860; $34.42 \%$ ) while remaining six states accounted for $28.5 \%$ $(n=2638)$ responses. The majority of the respondents were from 18 to 30 years of age $(3346 ; 40.27 \%$ ) with $46.11 \%$ (3831) of participants being male and $53.89 \%$ (4478) female. A higher number of respondents were married $(5222 ; 62.85 \%)$ and lived in urban localities (3799; $45.72 \%$ ). The literacy level was balanced in the sample, as people with graduate and higher qualification were $51.47 \%$ (4277) while $48.53 \%$ (4032) attained education up to intermediate level. About $27.81 \%$ (2311) of respondents were either unemployed or students while least number of respondents was from health-care segments (441; 5.31\%).
Table 1: Socio-demographic characteristics of the respondents $(n=8309)$

\begin{tabular}{|c|c|c|}
\hline Demographic variable & $\mathbf{n}$ & Percentage \\
\hline \multicolumn{3}{|l|}{ Age } \\
\hline $18-30$ years & 3346 & 40.27 \\
\hline $31-40$ years & 1969 & 23.69 \\
\hline $41-50$ years & 1317 & 15.85 \\
\hline $51-60$ years & 903 & 10.87 \\
\hline Above 60 years & 774 & 9.32 \\
\hline \multicolumn{3}{|l|}{ Gender } \\
\hline Male & 3831 & 46.11 \\
\hline Female & 4478 & 53.89 \\
\hline \multicolumn{3}{|l|}{ State } \\
\hline Arunachal Pradesh & 250 & 3.01 \\
\hline Assam & 257 & 3.09 \\
\hline Manipur & 3081 & 37.08 \\
\hline Meghalaya & 811 & 9.76 \\
\hline Mizoram & 272 & 3.27 \\
\hline Nagaland & 514 & 6.19 \\
\hline Sikkim & 264 & 3.18 \\
\hline Tripura & 2860 & 34.42 \\
\hline \multicolumn{3}{|l|}{ Residential area } \\
\hline Rural & 3301 & 39.73 \\
\hline Urban & 3799 & 45.72 \\
\hline Semi-urban & 1209 & 14.55 \\
\hline \multicolumn{3}{|l|}{ Marital status } \\
\hline Married & 5222 & 62.85 \\
\hline Unmarried & 3087 & 37.15 \\
\hline \multicolumn{3}{|l|}{ Education } \\
\hline Up to Junior Basic & 1368 & 16.46 \\
\hline Secondary & 2664 & 32.06 \\
\hline Graduation & 3328 & 40.05 \\
\hline PG and above & 949 & 11.42 \\
\hline \multicolumn{3}{|l|}{ Occupation } \\
\hline Health worker & 441 & 5.31 \\
\hline Govt. job & 1023 & 12.31 \\
\hline Pvt. job and Business & 1725 & 20.76 \\
\hline Unemployed and Student & 2311 & 27.81 \\
\hline Homemaker & 1731 & 20.83 \\
\hline Others & 1078 & 12.97 \\
\hline \multicolumn{3}{|l|}{ Chronic illness } \\
\hline Yes & 1284 & 15.45 \\
\hline No & 7025 & 84.55 \\
\hline \multicolumn{3}{|l|}{ Prophylactic medicine } \\
\hline Allopathic medicine & 242 & 2.91 \\
\hline Ayurvedic medicine & 119 & 1.43 \\
\hline Homoeopathic medicine & 4116 & 49.54 \\
\hline Unani medicine & 9 & 0.11 \\
\hline Siddha medicine & 4 & 0.05 \\
\hline Local/Folk medicine & 139 & 1.67 \\
\hline $\begin{array}{l}\text { I did not took any medicine for } \\
\text { prevention from COVID- } 19\end{array}$ & 2921 & 35.16 \\
\hline $\begin{array}{l}\text { Combination of more than one system of } \\
\text { medicine }\end{array}$ & 759 & 9.14 \\
\hline \multicolumn{3}{|l|}{ Source of information } \\
\hline $\begin{array}{l}\text { International health organization, for } \\
\text { example, WHO }\end{array}$ & 141 & 1.70 \\
\hline Government sites and media & 231 & 2.78 \\
\hline Social media (WhatsApp, Facebook, etc.) & 686 & 8.25 \\
\hline News media (TV, radio, newspaper, etc.) & 2374 & 28.57 \\
\hline Journals/Magazines & 10 & 0.12 \\
\hline Others & 17 & 0.21 \\
\hline Multiple source & 4850 & 58.37 \\
\hline \multicolumn{3}{|l|}{ Tested for COVID-19 } \\
\hline Yes & 240 & 2.89 \\
\hline No & 8069 & 97.11 \\
\hline \multicolumn{3}{|l|}{ Test result (out of 240 ) } \\
\hline Positive & 8 & 3.33 \\
\hline Negative & 232 & 96.67 \\
\hline \multicolumn{3}{|l|}{ Family member tested positive } \\
\hline Yes & 76 & 0.92 \\
\hline No & 8,233 & 99.08 \\
\hline
\end{tabular}


Information on COVID-19 was accessed from multiple media sources (4850; 58.37\%) with news media alone $(2374 ; 28.57 \%)$ being accessed most commonly by the respondents.

Only 15.45\% (1284) of respondents suffered from some chronic illness. The majority of people took homoeopathic medicine (4116; $49.54 \%)$ as prophylaxis for immune booster. $240(2.89 \%)$ respondents tested themselves for COVID-19 and only eight (3.33\%) of them found positive. At least one of the family members of $76(0.92 \%)$ respondents tested positive for COVID-19.

\section{Knowledge, attitude, practices, and perception}

Most of the participants entered correct responses for common symptoms of COVID-19 such as fever (8059; 96.99\%), dry cough (7596; 91.42\%), and shortness of breath (7231; 87.03\%) although the knowledge of less common symptoms such as conjunctivitis (1148; $13.82 \%)$, skin manifestations $(1980 ; 23.83 \%)$, and others were not found adequate. A significant number of respondents had correct knowledge on wearing facemask $(7607 ; 91.55 \%)$, mode of spread of COVID-19 (7522; 90.53\%), preventive measures (7411; 89.19\%), etc. Interestingly, the awareness on transmission of COVID-19 from asymptomatic individuals $(4133 ; 49.74 \%)$ and newspaper or currency notes $(950 ; 11.43 \%)$ was found wanting. In the attitude section, majority of the respondents agreed that lockdown $(6445 ; 77.57 \%)$ and social distancing $(6769 ; 81.47 \%)$ will help in preventing spread of COVID-19. Threat to healthcare workers $(6518 ; 78.45 \%)$ and importance of reporting suspected COVID case to health authorities (6903; 83.08\%) was mostly answered in agreement. The practice of wearing a facemask was adopted by $85.08 \%$ (7069) and of washing hands always by $77.77 \%$ (6462) of respondents. Up to $97.41 \%$ (8094) people practiced social distancing, 93.58\% (7776) avoided visiting markets or crowded places and 95.35\% (7923) cleaned or disinfected high touch surfaces. Interestingly, 45.08\% (3746) of respondents never went to a health-care facility and instead opted for telemedicine consultation. Perception of NE people was that discovery of vaccine will help eliminate the disease $(6268 ; 75.44 \%$ ) and traditional medicine and homeopathy will be effective as preventive and curative medicine (5197; 62.54\%). Only 19.56\% (1625) of the respondents were afraid of being infected with COVID-19. More than half of the respondents (4583; 55.15\%) believe that fear, phobia, etc., may decrease immunity and chance of getting an infection will be increased (Supplementary Material).

Majority of the respondents scored good or average KAP scores. The scores were in poor category only for $12.3 \%$ (1022) under knowledge, $13.61 \%$ (1131) under attitude, $12.67 \%$ (1053) under practices, and $27.48 \%$ (2283) of respondents under perception section (Table 2). The mean score (Standard Deviation) of knowledge was 7.137 (2.111), attitude 16.132 (3.277), practices 9.379 (2.207), and perception was 13.583 (2.204). The scores of four KAP categories significantly differed across all the demographic variables $(\mathrm{p}<0.001)$ exception for practices score being non-significant for chronic illness $(\mathrm{p}=0.221)$ and perception score being non-significant for gender $(\mathrm{p}=0.30)$ (Table 3$)$.

The knowledge on COVID-19 was good among people of Mizoram, followed by AP and Sikkim ( $\mathrm{p}<0.001)$. People of AP, Sikkim, and Nagaland $(p<0.001)$ have a good attitude. People of Sikkim, AP, and Assam adopted good practices $(\mathrm{p}<0.001)$ and residents of Manipur, Nagaland, and Tripura had positive perception $(\mathrm{p}<0.001)$.
All four sections were significantly associated with good scores among married persons $(p<0.001)$ and female gender $(p<0.05)$. Good knowledge and practice were significantly associated with age group 18-30 years, good attitude with 51-60 years, and good perception with age above 60 years $(\mathrm{p}<0.001)$. Respondents with education up to intermediate had good perception while postgraduate qualified persons had good remaining KAP scores $(\mathrm{p}<0.001)$. Similarly, good knowledge score was significantly associated with people living in semi-urban localities, working in a Government job and suffering from some chronic illness $(\mathrm{P}<0.001)$. People residing in urban areas had good attitude, practices, and perception while healthcare workers had good attitude and practices with homemakers having good perception $(p<0.001)$. People suffering from chronic illness had good attitude and perception $(\mathrm{p}<0.001)$ (Tables 4 and 5).

\section{DISCUSSION}

Amidst the increasing threat of COVID-19 in India, preventive measures play an important role. The government has utilized every possible medium for dissemination of health education amongst the masses. Along with provision of proper health education, the implementation of prevention strategies at personal level is a challenge in this pandemic. The attitudes of individuals and the existing social stigmas create a difference between education imparted and the actual practices of individuals. NE India is a difficult location in the country in respect of the communicability and accessibility of information and healthcare facilities. With more than 145 tribes in the region and diverse languages spoken, the communication of health education and personal hygiene practices is very challenging [14]. This study assessed the health education status of residents of NER and translation of the communication into their attitudes, practices and perception.

Knowledge about a disease is an essential component that shall always be reflected in the attitude and practices of the people. In this study, it was observed that people residing in urban areas displayed better knowledge compared to the rural population. Knowledge score was highest in Mizoram which may be attributed to the fact that Mizoram ranks $3^{\text {rd }}$ in the literacy rates of country after Kerala and Lakshadweep [15]. Knowledge score is higher in a younger age group as they are very well acquainted with multiple information sources especially the internet. Participants in majority (96.99\%) were aware of the presence of clinical symptom of fever in COVID-19 which is in sharp contrast to $18.2 \%$ knowledge of fever in another Indian study [16]. Dry cough and shortness of breath were known by $91.42 \%$ and $87.03 \%$ of participants, respectively, while $85.49 \%$ people have correct knowledge about incubation period which correlates with Indian study [17]. Transmission of COVID-19 through respiratory droplets was known to $90.53 \%$ participants as observed in a study from Jammu and Kashmir [18]. Contrary to the present study, knowledge of transmission was found in only $29.5 \%$ general population and $62 \%$ health-care professionals which further establishes the fact that dissemination of more information and awareness is required among the mass $[16,19]$. Social distancing is important to reduce the spread and was approved by $81.47 \%$ respondents similar to other study [16]. The study population not being aware of transmission by asymptomatic patients is a matter of concern and proper knowledge to the general population regarding this aspect is imperative. Scientists have reported the spread of COVID19 through items such as newspapers, currency notes, and household articles differently and therefore the idea of such transmission is often misinterpreted. As the knowledge about

Table 2: KAP score of the participants $(n=8309)$

\begin{tabular}{lllll}
\hline & Knowledge n (\%) & Attitude n (\%) & Practices n (\%) & Perception n (\%) \\
\hline Good & $4571(55.01)$ & $3668(44.15)$ & $4578(55.09)$ & $531(6.39)$ \\
Average & $2716(32.69)$ & $3510(42.24)$ & $2678(32.23)$ & $5495(66.13)$ \\
Poor & $503(6.05)$ & $816(9.82)$ & $966(11.63)$ & $2019(24.30)$ \\
Very poor & $519(6.25)$ & $315(3.79)$ & $87(1.05)$ & $264(3.18)$ \\
\hline
\end{tabular}

n: number; \%: percentage 


\begin{tabular}{|c|c|c|c|c|}
\hline & $\Xi$ & 六 & $\stackrel{m}{0}$ & $\begin{array}{l}\text { Qे } \\
\text { : }\end{array}$ \\
\hline & 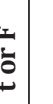 & 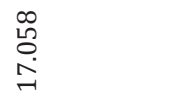 & $\begin{array}{l}\stackrel{0}{0} \\
\stackrel{\leftrightarrow}{-}\end{array}$ & $\begin{array}{l}\infty \\
\stackrel{\infty}{*} \\
\stackrel{\sim}{H}\end{array}$ \\
\hline ฮี & 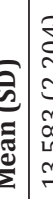 & 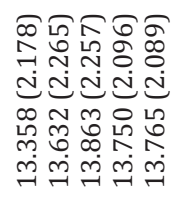 & 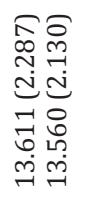 & 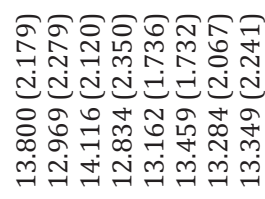 \\
\hline & $\underline{\Xi}$ & $\stackrel{0}{0}$ & $\begin{array}{l}\stackrel{8}{\circ} \\
\stackrel{0}{*}\end{array}$ & $\stackrel{\circ}{\circ}$ \\
\hline
\end{tabular}

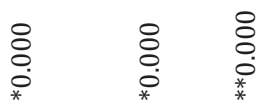

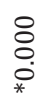

$\stackrel{8}{\circ}$

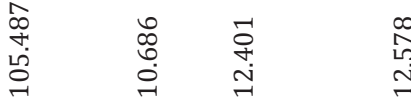

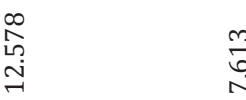

๙ิำล

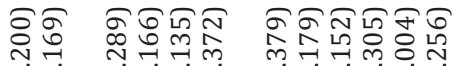

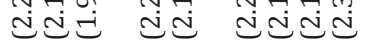
did $d$ d d $d$

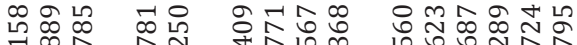
mig m

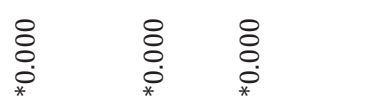

$\underset{*}{\circ}$

$\underset{\text { กี }}{\text { ปิ }}$

章

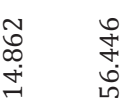

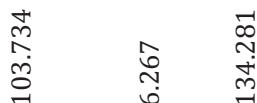

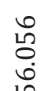

$\stackrel{\sim}{\sim}$

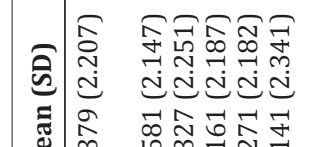

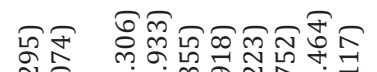

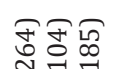

오ำ

4. ñ

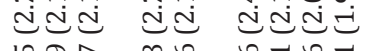

ن⿺辶寸

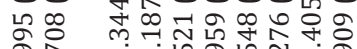

นू. 소․

范

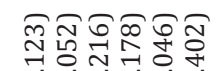

త్రతd త্ర

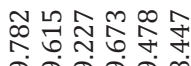

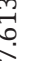

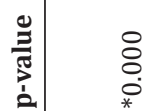

$\begin{array}{ll}8 & 8 \\ 0 & 0 \\ * & 0 \\ *\end{array}$

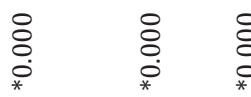

:

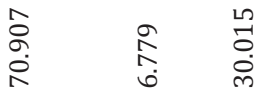

$\underset{\text { I }}{\stackrel{N}{N}}$

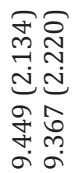

똫ำำ

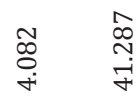

\section{곡동ำ}

\section{중}

\section{จ땀ำ}

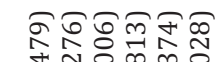

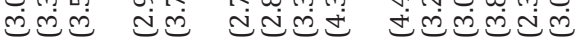

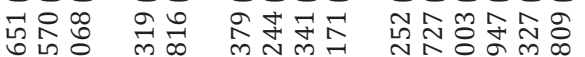

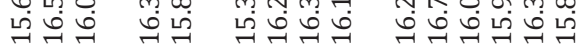

๑ क्री

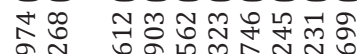

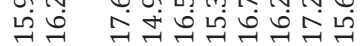

$\underset{*}{\circ}$

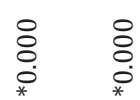

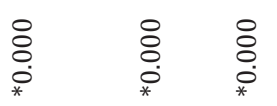

$\stackrel{\circ}{\circ}$

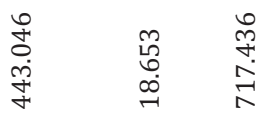

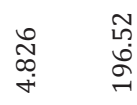

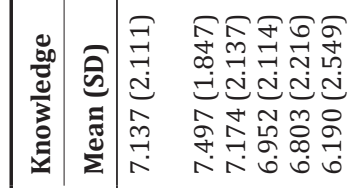

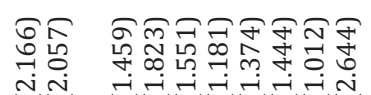

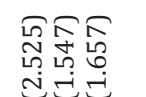

촐

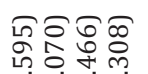

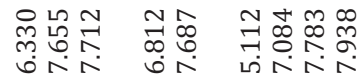
తid

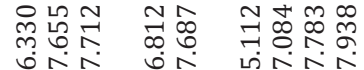

ํㅗㄱ

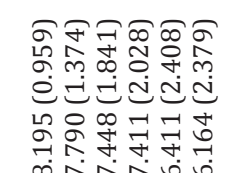

\ุำ

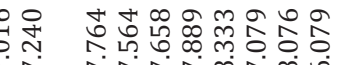
ט소

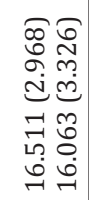

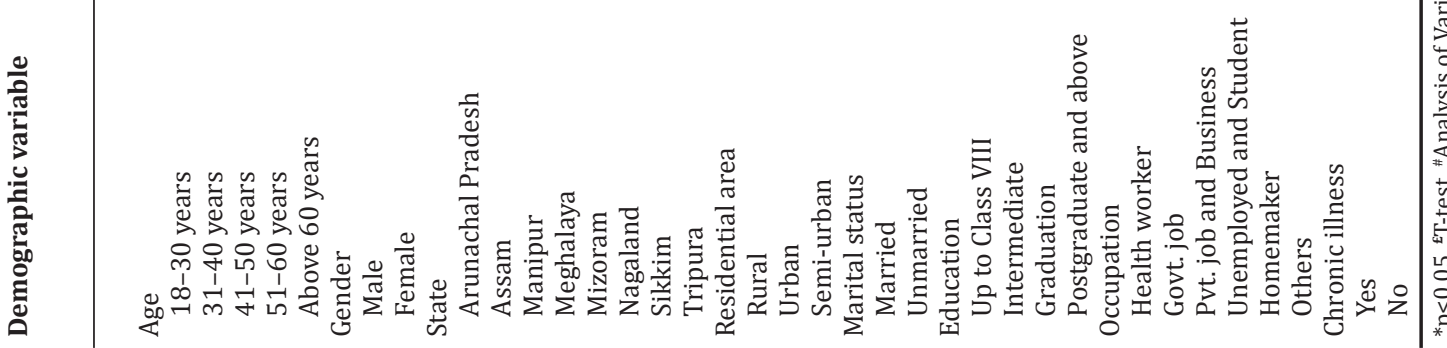




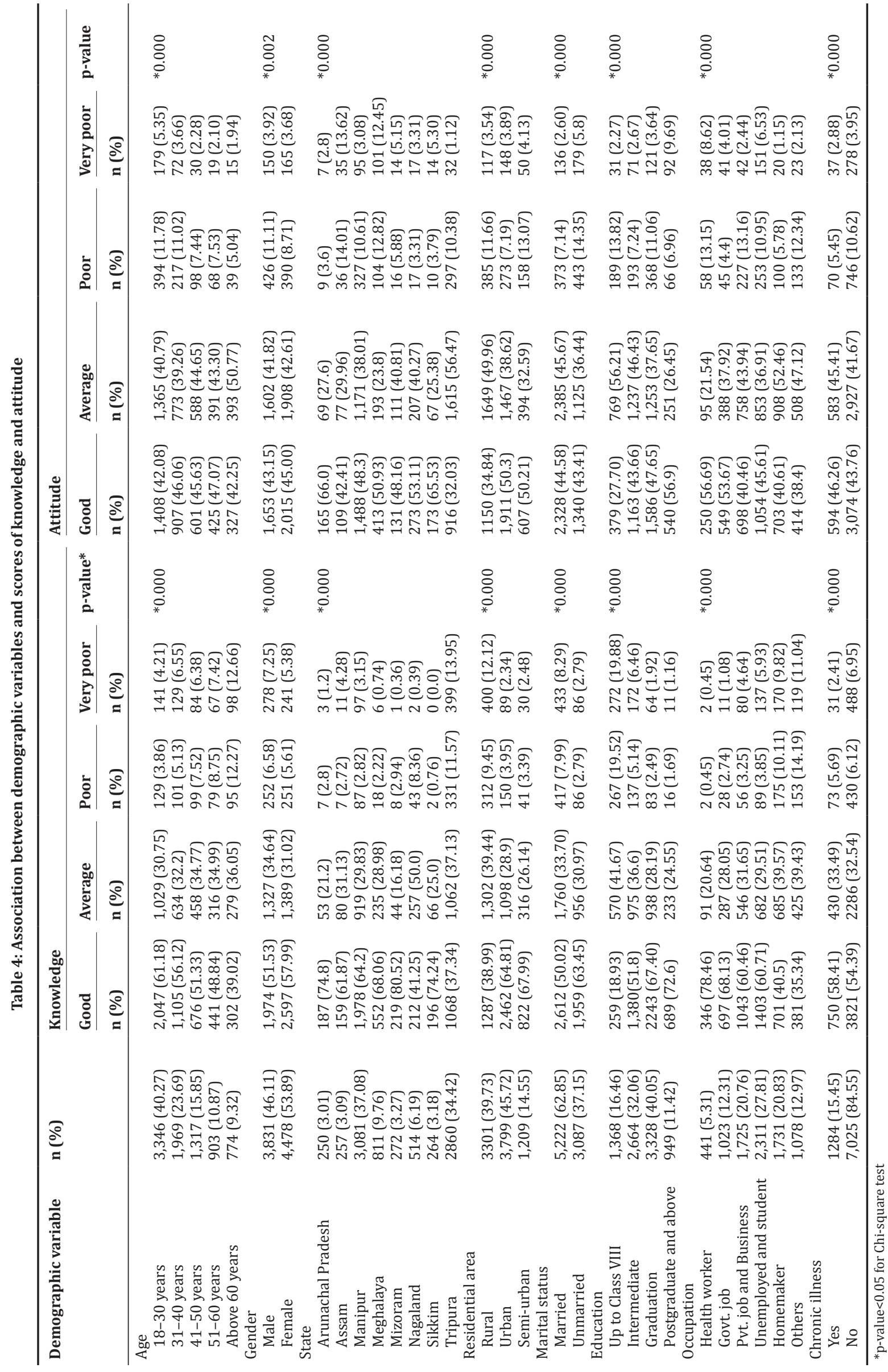




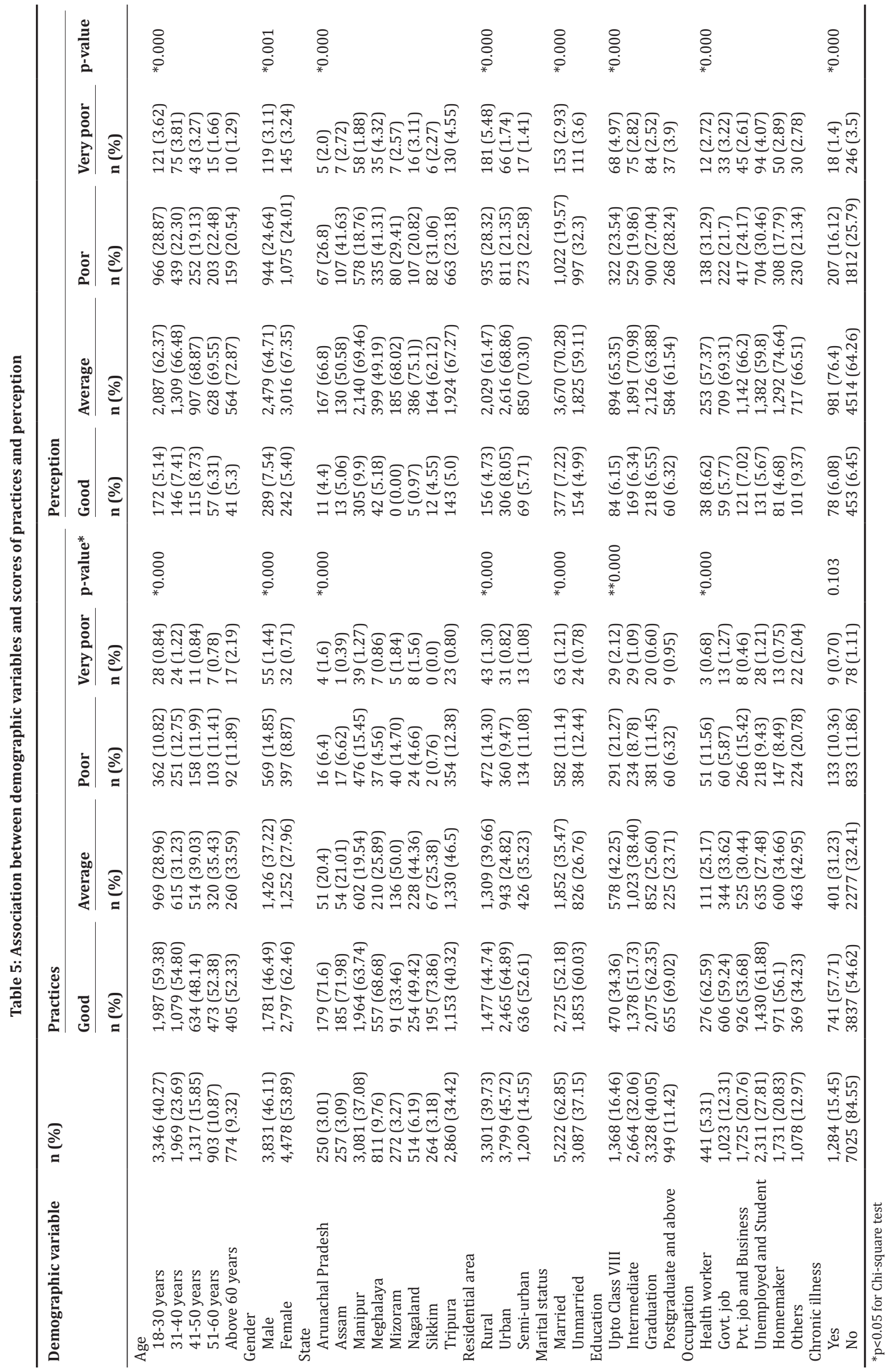


transmission is changing day by day, being alert about fomite-borne transmission as observed in other respiratory infections is essential.

Hand hygiene and social distancing were positively associated with better knowledge scores which was evident from the fact that majority of population have taken preventive measures by avoiding going to crowded places $(93.58 \%)$ and hospitals $(45.08 \%)$. Practice of frequent hand washing $(77.77 \%)$ in this study was less compared to other Indian studies that reported this practice in $85 \%, 99 \%$, and $87 \%$ population [16-18]. Practice of wearing face masks $(85.08 \%)$ seems to increase with the pandemic spreading widely as only $37 \%$ population used facemask at the time of declaration of pan lockdown in India [16]. Respondents from Sikkim state had shown good practices and interestingly Mizoram showed least among all other NE states considering higher literacy rate and good knowledge about COVID-19. Probably due to fewer respondents from Mizoram, the actual objective was not reflected properly. The dissemination of education and awareness materials by the health authorities increased the understanding of the pandemic and the behavioral change was reflected in good practices adopted.

The higher qualified, educated, health workers, and females had shown greater positive attitude. Almost $77 \%$ respondents extended their support for lockdown in preventing spread of COVID-19 which is also seen in other Indian study [18]. AP residents showed more positive attitude although very few responses were received from that particular state. About $72 \%$ respondents in the study had positive perceptions about COVID-19 which was found more in Manipur and least in Meghalaya. The optimistic attitude and perception of the respondents may be attributed to the measures taken by the Indian government such as nationwide lockdown, suspension of all domestic and international flights, closure of religious places, schools, and universities in mitigating the spread of the virus.

It is well established through public health research that disease control is directly linked with population KAP about a particular disease. The incidence of the pandemic is significantly lower in $\mathrm{NE}$ as compared to rest of India as whole of NER has contributed only 3.76\% of the disease burden [20]. It might be due to fair knowledge, optimistic attitudes, appropriate practices, and good perceptions towards COVID-19 the people showed in this study. Strength of the study is large sample size with participants from both the genders; different age groups and education level recruited. It would have been better if there were more responses from AP, Assam Mizoram, and Sikkim.

There are some limitations to this study. First, the study was conducted online so understanding of English language, internet access, and computer literacy of respondents might have affected the response to the questionnaire. However, online surveys have been found as an effective way to assess the KAP level in population because of its convenience and low cost. Second, the method of convenient sampling adopted leads to unequal responses from all the states of NE. Third, the outcomes were self-reported which carries a risk of source bias. Fourth, the Google form was also shared among the patients visiting the homeopathic institutions and a significant proportion of respondents in this study preferred homeopathy as prophylaxis for COVID-19. This finding, though, is corroborated by the fact that Government has distributed homoeopathic prophylaxis medicine to a large population throughout the country [21,22]. Despite the limitations, this study provides robust data on KAP about COVID-19 specifically for NE India population.

\section{CONCLUSION}

The study is a rigorous and needed exercise in these times of public health emergency for evidence-based policymaking. The study highlights good knowledge of participants but there is certainly scope for improvement in practice of preventive measures. Although few states showed better knowledge and practice, the focus on behavioral change communication in all NE states could be strengthened, especially in rural areas. Advocacy based on the comprehensive list of symptoms for
COVID-19 may also be bolstered, as the knowledge is limited to the few common symptoms. The study underscores that homeopathy remains one of the major prophylaxis as immune booster among the states. The states may take continued cognizance of the AYUSH system benefits and boost efforts for improvement of knowledge, immunity-boosting, and self-care practices suggested in the AYUSH systems of medicine.

\section{ACKNOWLEDGMENT}

The authors are thankful to Senior/Junior Research Fellow (SRF/ JRF), namely, Dr. Gouri Devi, Dr. Thadoi Potsangbam, Dr. Amita Oinam, Dr. Lily Anal, and Dr. Maibam Lilakanta; Miss Saya Devi (Multitasking Attendant [MTA]), Mrs. Rameshwari Devi (Upper Division Clerk [UDC]), and Mrs. Angom Silvia (Data Entry Operator [DEO]) from Manipur for their contribution in the study. The authors acknowledge the sincere efforts of Md Mukta Miah, Miss Lipika Deb, (DEO) Mr. Jyoti Bikash Chakma, (Pharmacy Assistant) from Tripura; Mrs. Rambuatsaihi (UDC) from Mizoram; Dr. Inty Siram, Medical Officer (MO) from AP; Dr. Tanmoy Maity (JRF) and Dr. Pramila Upreti (MO) from Sikkim; Dr. Bendangyanger (SRF), Mrs. J. Keppen (UDC) and Mr. Imtisanen (MTA) from Nagaland in distribution of Google forms widely among their contacts. We also acknowledge Dr Srimonti Sanyal, Postgraduate Trainee from Kolkata for her contribution to the study.

The authors also convey their gratitude to NGOs, Doctors forums and all persons who were involved in this study directly or indirectly. Most importantly, authors thank all respondents from NE states who participated in this study.

\section{AUTHOR CONTRIBUTION}

AS and RB: Conceptualization, methodology, supervision and visualization of the study. AS, RB, RCS, PKS, LK, HB, SKT, BB, TN, and AC: Drafting of final questionnaire and conduction of the study. AS in data curation. PS in data analysis. AS, RB, RCS, LK, HB, BB, TN, and AC: Writing the original draft. AS, RB, RCS, PKS, LK, HB, SKT, BB, TN, AC, and PS: Reviewing and editing. All authors read and approved the final paper.

\section{CONFLICT OF INTEREST}

None declared.

\section{FUNDING SUPPORT}

It was a web-based study and did not require any funding support

\section{REFERENCES}

1. World Health Organization. Coronavirus Disease (COVID-19). Geneva: World Health Organization; c2020. Available from: https:// www.who.int/emergencies/diseases/novel-coronavirus-2019. [Last accessed on 2020 Aug 26].

2. World Health Organization. Statement on the Second Meeting of the International Health Regulations (2005) Emergency Committee Regarding the Outbreak of Novel Coronavirus (2019-nCoV). Geneva: World Health Organization; c2020. Available from: https://www.who. int/news-room/detail/30-01-2020-statement-on-the-second-meetingof-the-international-health-regulations-(2005)-emergency-committeeregarding-the-outbreak-of-novel-coronavirus-(2019-ncov). [Last accessed on 2020 Aug 26].

3. Parashar U. Covid-19: Northeast Reports Fewer Cases, Manipur Has no New Positive Case as of Sunday. Hindustan Times; 2020. Available from: https://www.hindustantimes.com/india-news/manipurhas-no-covid-19-case-as-of-sunday-says-cm-biren-singh/storysfBnD2QbbIK4Aq5rxW2kLO.html. [Last accessed on 2020 Aug 26].

4. World Health Organization. Coronavirus Disease (COVID-19) Situation Report-162. Geneva: World Health Organization; c2020. Available from: https://www.who.int/docs/default-source/ coronaviruse/20200630-covid-19-sitrep-162.pdf?sfvrsn=e00a5466_2. [Last accessed on 2020 Aug 26].

5. Deccan Herald. Coronavirus India Update: State-wise Total Number of Confirmed Cases, Deaths. New Delhi: Deccan Herald; 2020. Available from: https://www.deccanherald.com/national/coronavirus- 
india-update-state-wise-total-number-of-confirmed-cases-deaths-onjune-30-855264.html. [Last accessed on 2020 Aug 26].

6. Azlan AA, Hamzah MR, Sern TJ, Ayub SH, Mohamad E. Public knowledge, attitudes and practices towards COVID-19: A crosssectional study in Malaysia. PLoS One 2020;15:e0233668.

7. Al-Hanawi MK, Angawi K, Alshareef N, Qattan AM, Helmy HZ, Abudawood Y, et al. Knowledge, attitude and practice toward COVID-19 among the public in the Kingdom of Saudi Arabia: A crosssectional study. Front Public Health 2020;8:217-26.

8. Clements JM. Knowledge and behaviors toward COVID-19 among US residents during the early days of the pandemic: Cross-sectional online questionnaire. JMIR Public Health Surveill 2020;6:e19161.

9. Zhong BL, Luo W, Li HM, Zhang QQ, Liu XG, Li WT, et al. Knowledge, attitudes, and practices towards COVID-19 among Chinese residents during the rapid rise period of the COVID-19 outbreak: A quick online cross-sectional survey. Int J Biol Sci 2020;16:1745-52.

10. Eysenbach G. Improving the quality of web surveys: The checklist for reporting results of internet E-surveys (CHERRIES). J Med Intern Res 2004;6:e34.

11. Ministry of Health and Family Welfare, Government of India. FAQs: Detail Question and Answers in COVID-19 for Public. New Delhi: Ministry of Health and Family Welfare, Government of India; 2020. Available from: https://www.mohfw.gov.in/index.html. [Last accessed on 2020 Aug 26].

12. Ministry of AYUSH, Government of India. COVID-19 Related Information. New Delhi: Ministry of AYUSH, Government of India; 2020. Available from: https://www.ayush.gov.in. [Last accessed on 2020 Aug 26].

13. Centers for Disease Control and Prevention. Coronavirus Disease 2019. Atlanta: Centers for Disease Control and Prevention; 2019. Available from: https://www.cdc.gov/index.htm. [Last accessed on 2020 Aug 26].

14. Ali AN, Das I. Tribal situation in North East India. Stud Tribes Tribals $2003 ; 1: 141-8$
15. Office of the Registrar General and Census Commissioner, India. State of Literacy: Ranking of States and Union Territories by Literacy Rate. New Delhi: Office of the Registrar General and Census Commissioner, India; 2011. Available from: https://www.censusindia.gov.in/2011prov-results/data_files/india/Final_PPT_2011_chapter6.pdf. [Last accessed on 2020 Aug 26].

16. Roy D, Tripathy S, Kar SK, Sharma N, Verma SK, Kaushal V. Study of knowledge, attitude, anxiety and perceived mental healthcare need in Indian population during COVID-19 pandemic. Asian J Psychiatry 2020;51:102083.

17. Parikh PA, Shah BV, Phatak AG, Vadnerkar AC, Uttekar S, Thacker N, et al. COVID-19 pandemic: Knowledge and perceptions of the public and healthcare professionals. Cureus 2020;12:e8144.

18. Dkhar SA, Quansar R, Saleem SM, Khan SM. Knowledge, attitude, and practices related to COVID-19 pandemic among social media users in J\&K, India. Indian J Public Health 2020;64:205-10.

19. Modi PD, Nair G, Uppe A, Modi J, Tuppekar B, Gharpure AS, et al. COVID-19 awareness among healthcare students and professionals in Mumbai metropolitan region: A questionnaire-based survey. Cureus 2020;12:e7514.

20. COVID India. COVID-19 Tracker Updates for India for State Wise and District Wise Data. New Delhi: COVID India; c2020. Available from: https://www.covidindia.org/\#pll switcher. [Last accessed on 2020 Aug 31].

21. Ghosh S. Covid Prophylaxis: Govt Distributed Arsenicum Album-30 to Half of State's Population in Five Months. The Indian Express; 2020. Available from: https://www.indianexpress.com/article/india/covidprophylaxis-govt-distributed-arsenicum-album-30-to-half-of-statespopulation-in-five-months-6566061. [Last accessed on 2020 Aug 28].

22. Kunnathoor P. Manipur Ayush Dept Directs Ayush Hospitals to Distribute Arsenicum Album 30 as Preventive Medication Against nCoV Infection; 2020. Available from: http://www.pharmabiz.com/ NewsDetails.aspx ?aid $=121184 \&$ sid $=1$. [Last accessed on 2020 Aug 28]. 